Disponível em:

http://editora.unoesc.edu.br/index.php/race

Race, Joaçaba, v. 15, n. 3, p. 843-870, set./dez. 2016

\title{
PROGRAMA NETUNO: INOVAÇÃO PARA A MELHORIA DA GESTÃO NA MARINHA DO BRASIL
}

Neptune Program: innovation to improve management in the Brazilian Navy

Flávio Sergio Rezende Nunes Souza

E-mail: flavio.nunes@dadm.mar.mil.br

Mestre em Administração pela Escola Brasileira de Administração Pública e de Empresas (EBAPE-FGV);

Assessor de Gestão do Programa Netuno; Diretoria de Administração da Marinha. Endereço para contato: Ilha das Cobras, Ed. Almirante Gastão Motta, $2^{\circ}$ andar, s/n, 20091-000 Centro, Rio de Janeiro, Rio de Janeiro, Brasil.

Valentina Gomes Haensel Schmitt

E-mail: valentinaschmitt@hotmail.com

Doutora em Adminsitração pela Escola Brasileira de Administração Pública e de Empresas (EBAPE-FGV); Mestre e Bacharel em Administração pela Universidade Federal de Santa Catarina.

\begin{abstract}
Anderson Fernandes Pinto
E-mail: andfernandes.rj@gmail.com Mestre em Administração pela Universidade Federal do Rio de Janeiro (COPPEAD-UFRJ); Assessor de Gestão do Programa Netuno; Diretoria de Administração da Marinha.

Claudio Gil Favero

E-mail: favero@dadm.mar.mil.br Mestre em Administração Pública pela Escola Brasileira de Administração Pública e de Empresas (EBAPE-FGV); Especialista em Gestão Empresarial pela Fundação Getúlio Vargas; Chefe do Departamento de Gestão Administrativa; Diretoria de Administração da Marinha.
\end{abstract}

Artigo recebido em 07 de julho de 2015. Aceito em 27 de junho de 2016. 
Resumo

Frequentes são os esforços nas organizações públicas no sentido de modernização administrativa por meio da utilização do Modelo de Excelência em Gestão Pública (MEGP), que foi concebido a partir da premissa da necessidade de ser excelente sem deixar de ser público. No Brasil, o modelo é aplicado pelo Governo Federal por intermédio do Programa Nacional de Gestão Pública e Desburocratização (Gespública), criado em 2005. A Marinha do Brasil (MB), enquanto organização pública, customizou o modelo utilizado pelo Gespública às suas especificidades, criando o Programa Netuno em 2006. Esse programa fomenta a cultura da inovação na instituição, um dos fundamentos da excelência gerencial que formam a base do MEGP. O objetivo com este trabalho foi analisar como o Programa Netuno tem incentivado a implementação de iniciativas inovadoras de forma a contribuir com a melhoria da gestão na Marinha. Para tanto, foram analisadas "boas práticas” monitoradas pelo Programa por meio de um estudo de caso, de caráter descritivo, utilizando-se a análise de conteúdo para a avaliação dessas práticas. Constatou-se que o Programa Netuno, por meio de seus instrumentos de gestão, constitui-se em uma inovação sistêmica, facilitando o surgimento de inovações nas unidades da MB no sentido bottom-up. Entre as iniciativas analisadas, as que mais se destacaram foram aquelas que refletem o foco no desenvolvimento da força de trabalho, fato que corrobora as diretrizes do Programa Netuno - relacionadas à capacitação profissional e à valorização do elemento humano.

Palavras-chave: Administração pública. Excelência em gestão. Inovação. Marinha do Brasil. Programa Netuno.

\begin{abstract}
Frequently are efforts in public organizations towards administrative modernization through the use of the Public Management Excellence Model (MEGP), that has been designed on the premise that one must be excellent while being public. In Brazil, the MEGP is applied by the Federal Government through the National Program for Public Management and Debureaucratization (Gespública), created in 2005. Brazilian Navy, as a public organization, customized the model used by Gespública to their specificities, creating the Neptune Program in 2006. This program fosters a culture of innovation in this institution, one of the foundations of the managerial excellence that form the basis of MEGP. The objective of this study is to verify how the Neptune Program has encouraged the implementation of innovative initiatives in order to contribute to the improvement of management in the Navy. To reach this objective, a number of "good practices" monitored by the program were analyzed through a case study with descriptive nature, using content analysis to evaluate these practices. It is
\end{abstract}


observed that the Neptune program, through its management tools, is classified as a systemic innovation, facilitating the emergence of innovations in units of the Brazilian Navy in the bottom-up direction. Among the initiatives analyzed, those that stood out were those that reflect the focus on the development of the workforce, a fact that confirms the guidelines of the Neptune program - related to professional training and enhancement of the human element.

Keywords: Public Management. Management Excellence. Innovation. Brazilian Navy. Neptune Program.

\section{INTRODUÇÃO}

Durante a década de 1980, o mundo passou por uma grande crise econômica, que reduziu a taxa de crescimento dos países centrais pela metade, manteve a renda per capita dos países em desenvolvimento estagnada por 15 anos e levou ao colapso do regime soviético. Essa crise teve como causa fundamental a crise do Estado, que se configurou em três diferentes vertentes: fiscal, caracterizada pela crescente perda de crédito por parte do Estado e pela poupança negativa, inviabilizando as políticas públicas; do modo estatizante de intervenção do Estado no aspecto econômico e social, o que significou o esgotamento do Welfare State; e, do modelo burocrático de gestão pública, marcado pelos altos custos e pela baixa qualidade dos serviços públicos.

Em contraposição a esse contexto, surgiu o New Public Management (NPM), que acarretou uma série de reformas administrativas. As mudanças visavam à chamada administração gerencial, que possuía como características o aumento de flexibilidade, o crescimento da participação dos cidadãos, a adoção mais efetiva de filosofia da gestão da qualidade e, ainda, a adoção de métodos de gestão mais eficientes. Desde então, diversos países - em especial aqueles de tradição anglo-saxã - acabaram realizando reformas administrativas, com objetivo de fortalecer a capacidade de implementação de políticas pelo Estado.

No Brasil, também fundamentado na proposta de NPM, foi criado e desenvolvido pelo Ministério do Planejamento, Orçamento e Gestão (MP) o Programa Nacional de Gestão Pública e Desburocratização (Gespública). O objetivo era aumentar a competitividade das organizações públicas e contribuir para a melhoria da qualidade de vida do cidadão, instrumentalizando uma gestão pública por resultados e assegurando a obtenção de lucros sociais decorrentes de bons produtos e serviços. Esse Programa utiliza o Modelo de Excelência em Gestão Pública (MEGP) e possui como base os fundamentos da excelência, que incluem a cultura da inovação. 
Na administração pública a inovação se mostrou um novo e grande desafio, ao visar fomentar condições favoráveis à criatividade, experimentação e implementação de novas ideias agregadoras de valor às organizações.

No entanto, em relação ao estado atual da pesquisa relacionada à inovação no setor público, são observadas diversas limitações: consistem em uma realidade em que muito pouco pode ser quantificado (GOVINDARAJAN; TRIMBLE, 2010), abrindo espaço para a ambiguidade; desobrigação por parte das organizações em tornar públicas suas informações e iniciativas; redução do volume de pesquisas em inovação por parte da administração pública (MULGAN; ALBURY, 2003; SALAZAR; HOLBROOK, 2004; OLIVEIRA, 2012) e o fato de serem recentes (BRANDÃO; BRUNO-FARIA, 2013); atribuição do papel central de inovação aos empreendedores individuais e às empresas privadas, tornando a administração pública coadjuvante no processo (OLIVEIRA, 2012, p. 2); imagem de conservadorismo e burocracia das instituições públicas (MULGAN; ALBURY, 2003); literatura em inovação no setor público limitada em termos de investigações empíricas (BLOCH; BUGGE, 2013).

A inovação no setor público demonstrou potencial de provocar um intenso processo de transformação do Estado, produzindo benefícios generalizados para os cidadãos por meio da melhoria dos serviços públicos. Não obstante, essa preocupação se tornou urgente, pois o baixo desempenho das estruturas governamentais pode inviabilizar o alcance dos compromissos firmados pelos líderes na Declaração do Milênio e em outras conferências globais (UNITED NATIONS, 2009). Nesse contexto, mesmo diante da escassez de pesquisas na área, há que se reconhecer a diversidade de experiências inovadoras na administração pública (SALAZAR; HOLBROOK, 2004; SOUSA et al., 2013), principalmente em razão da falta da perspectiva de seu papel como protagonista de processos de inovação (KOCH; HAUKNES, 2005; LIMA; VARGAS, 2012).

Se no setor público existem poucas pesquisas que abordam a inovação, em relação às organizações militares estas são ainda mais escassas. Nesse contexto, surge a provocação acerca da relação entre características da cultura militar e iniciativas inovadoras nessas organizações, que são também consideradas exemplos de organização burocrática. Curiosamente, no Brasil, destaca-se a elevada frequência da participação das Forças Armadas em movimentos como o Concurso Inovação na Gestão Pública Federal - da Escola Nacional de Administração Pública (ENAP) - correspondendo a um total de 6,13\% das iniciativas inscritas - Exército (3,07\%), Marinha (1,86\%) e Aeronáutica (1,20\%) (FERRAREZI; AMORIM, 2007). 
Como exemplo, há aproximadamente uma década a Marinha do Brasil adotou o MEGP, por intermédio do Programa Netuno, customizando esse instrumento para suas necessidades. Desde então, esse Programa fomentou a cultura da inovação nas suas unidades, permitindo evoluções em suas práticas de gestão. Essas características tornam o Programa Netuno um caso relevante para a pesquisa, com possibilidade de identificação de iniciativas inovadoras passíveis de serem replicadas em outras organizações. Diante das lacunas relativas à inovação em organizações militares (OM) e da importância da inovação nas estruturas organizacionais, com este trabalho teve-se o objetivo de identificar como o Programa Netuno tem incentivado a implementação de iniciativas inovadoras na Marinha de forma a contribuir com a melhoria da gestão.

A próxima seção deste artigo é dedicada ao referencial teórico, em que são abordados: as reformas administrativas e o MEGP, aspectos atinentes à inovação no setor público e o Programa Netuno. Na terceira seção, é apresentada a metodologia utilizada para a realização da pesquisa. Na quarta seção apresentam-se os resultados. Na última seção, discorre-se sobre as potenciais repercussões dos achados e apresentam-se as considerações finais.

\section{REFERENCIAL TEÓRICO}

\subsection{AS REFORMAS ADMINISTRATIVAS E O MODELO DE EXCELÊNCIA EM GESTÃO PÚBLICA}

Historicamente, a administração pública brasileira passou por várias reformas administrativas, tendo como grandes marcos o Governo Vargas, que realizou o primeiro esforço deliberado, sistemático e continuado de modernização administrativa, denominado Reforma Burocrática, e a Reforma Desenvolvimentista, de 1967, que implementou estruturas e procedimentos padronizados introduzindo novos instrumentos de intervenção (LUSTOSA, 2008).

Em um segundo momento, a partir dos anos 1980, diversos governos realizaram mudanças substanciais em suas administrações públicas, utilizando novos discursos e práticas derivados do setor privado. O modelo burocrático, por consequência das suas disfunções, tornou-se muito criticado em termos de ineficiência, de morosidade e de seu caráter autorreferido.

A partir de então, novas propostas foram lançadas, de modo a se destacar o modelo preconizado para a estruturação e gestão da administração pública, conhecido como New Public Management (NPM) (SECCHI, 2009). 
Tornou-se evidente a percepção de que era preciso melhorar o desempenho da gestão pública, a qual deveria alcançar diversos objetivos, como a melhoria na qualidade da oferta de serviços públicos. O Plano Diretor da Reforma do Estado, em 1995, definiu as diretrizes para a implantação da administração gerencial no Brasil. Aspectos de desempenho, mediante o estabelecimento de indicadores e metas ousadas e factíveis, e o acompanhamento e a avaliação dos programas passaram a ser incluídos na agenda dessa reforma (MATIAS-PEREIRA, 2012).

Em meados dos anos 1980 nos Estados Unidos, diante da busca de novas tecnologias de gestão, especialistas analisaram organizações privadas que se destacavam, em busca de características comuns que as diferenciassem das demais. A identificação dessas características originou os critérios de avaliação do Malcolm Baldrige National Quality Award (MBNQA) nos EUA, premiação criada para estimular a melhoria da qualidade. Esses critérios foram considerados fundamentais para a formação de uma cultura de gestão voltada para a excelência e serviram de base para o Modelo de Excelência em Gestão (MEG) de diversos países, como Japão, Nova Zelândia, Austrália, Chile, Argentina e Brasil (FERREIRA, 2003).

No Brasil, o MEG foi introduzido pela Fundação Nacional da Qualidade (FNQ) - instituição privada, sem fins lucrativos, criada em 1991, por 39 organizações, para administrar o Prêmio Nacional da Qualidade (PNQ). O MEG do PNQ indica que a organização, para atingir a qualidade total, deve buscar atender a todos os oito critérios de excelência do modelo, promovendo ações que os satisfaçam. O modelo é fruto da experiência e pesquisa de diversas organizações e especialistas, em níveis nacional e internacional (MARSHALL JUNIOR et al., 2010).

O MEG e seus critérios de excelência encontram-se ilustrados na Figura 1 - representando um organismo vivo. O modelo funciona como um sistema, composto por elementos que interagem de forma sincronizada e harmônica. Além disso, necessita do adequado relacionamento com o ambiente externo. No MEG pode ser visualizado o ciclo de melhoria contínua dos processos organizacionais, o PDCA. ${ }^{1}$ Os critérios liderança, estratégias e planos, clientes e sociedade representam a fase de planejamento. Pessoas e processos representam a etapa de execução. O critério resultados constitui a fase de controle, e, por fim, informações e conhecimento formam a etapa de retroalimentação (MARSHALL JUNIOR et al., 2010). 


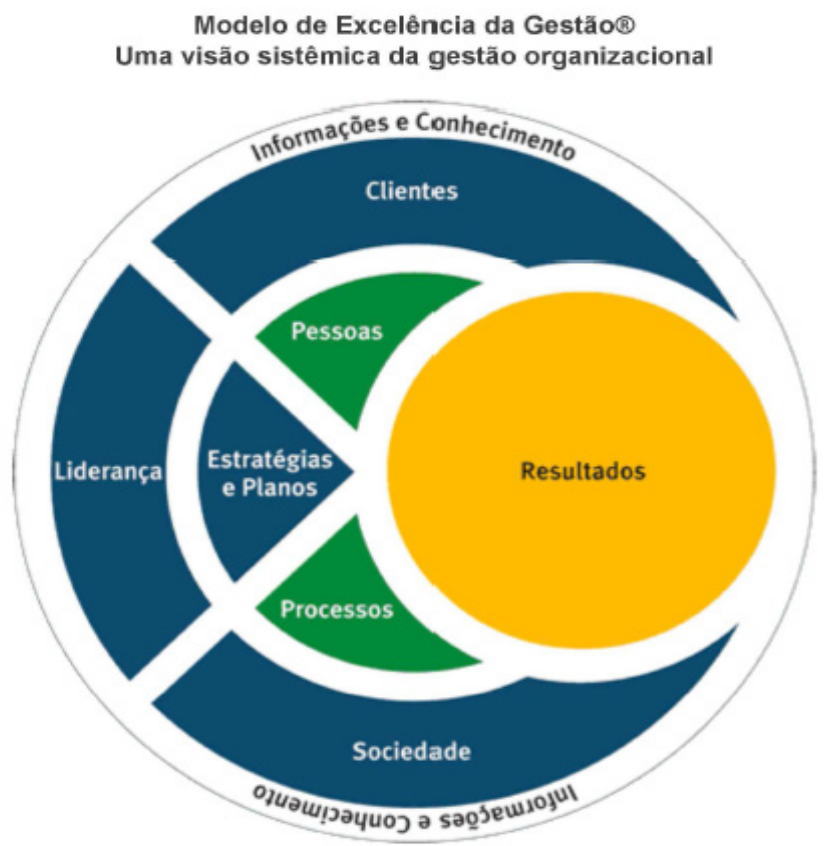

Fonte: Fundação Nacional da Qualidade (2014).

O MEGP é derivado do MEG, sendo estabelecido com base em modelos internacionais. Este reflete aspectos modernos no campo da gestão contemporânea e diferencia-se por considerar a natureza das organizações do setor público. O MEGP é "[...] concebido a partir da premissa segundo a qual é preciso ser excelente sem deixar de ser público.” (BRASIL, 2009c, p. 13). Esse modelo tem como alicerce princípios constitucionais próprios das organizações públicas, além de princípios da gestão de excelência contemporânea, constituindo-se pelos seguintes fundamentos: cultura da inovação; pensamento sistêmico; aprendizado organizacional; liderança e constância de propósitos; orientação por processos e informações; visão de futuro; geração de valor; comprometimento com as pessoas; foco no cidadão e na sociedade; desenvolvimento de parcerias; responsabilidade social; controle social; e, gestão participativa (BRASIL, 2014b).

A Administração Pública Federal adotou o MEGP por intermédio do Instrumento para Avaliação da Gestão Pública (IAGP), um conjunto de orientações para a avaliação da gestão, utilizado pelas organizações que aderiram ao Gespública. Em junho de 2014 foi apresentada a última atualização do modelo adotado, que se encontra 
representado no Diagrama 1. Esse instrumento foi customizado para a Marinha pelo Programa Netuno, com a finalidade de modernizar a gestão e fomentar a implementação de iniciativas inovadoras, em busca de um melhor desempenho institucional

Diagrama 1 - Modelo de excelência do Gespública

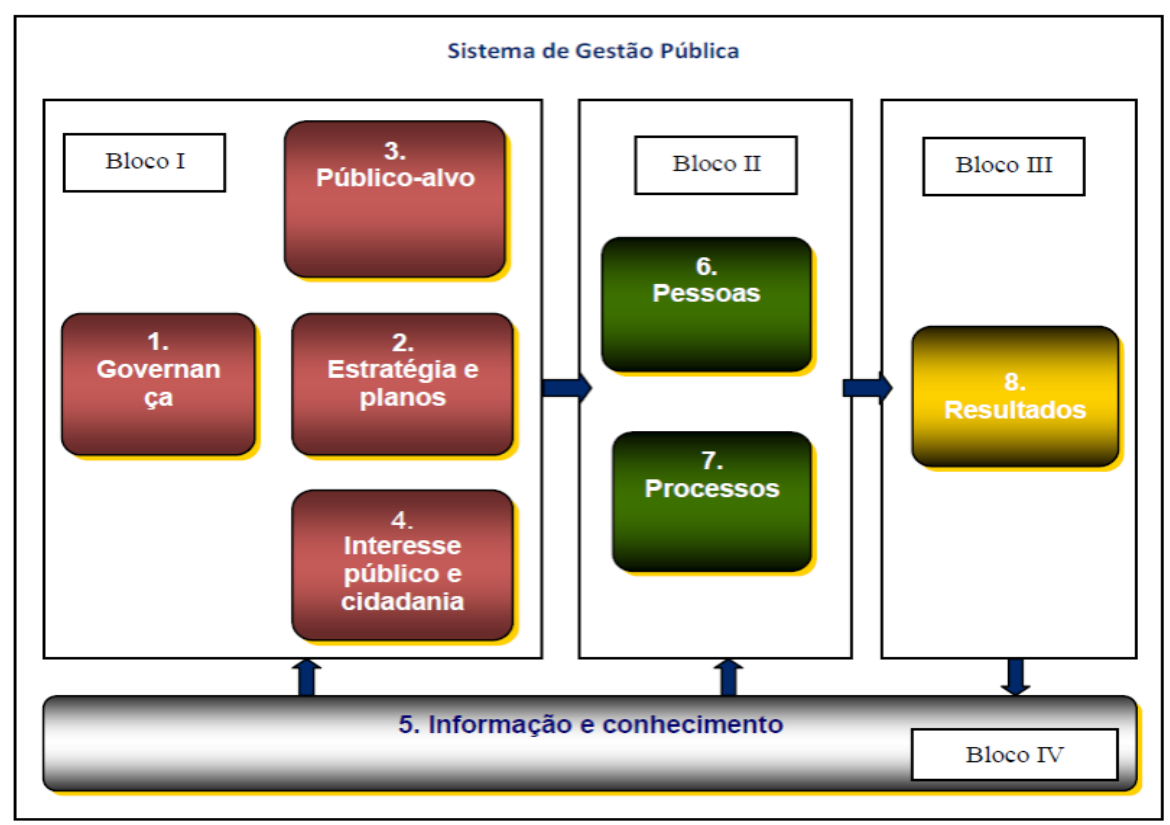

Fonte: Brasil (2014c, p. 20).

\subsection{INOVAÇÃO NO SETOR PÚBLICO}

A inovação no setor público, conforme já mencionado, configura-se em grande desafio tanto para o campo da prática quanto para o da pesquisa em gestão. Mesmo diante da vasta literatura sobre inovação, verifica-se a falta de consenso em relação ao tema (CANADA SCHOOL OF PUBLIC SERVICE, 2006). Schumpeter (1982) tem um papel pioneiro em relação à inovação. Para esse autor, esta consiste no processo de realizar novas combinações entre materiais e forças produtivas, o que gera novos produtos e desenvolvimento econômico. Esse processo dinâmico de substituição de antigas tecnologias por novas é denominado "destruição criadora”. No entanto, já surgem visões mais amplas, que incluem as inovações em serviços, e relacionadas a estas, as inovações no setor público (LIMA; VARGAS, 2012; BLOCH; BUGGE, 2013). 
Em um aspecto mais abrangente e resumido, inovação pode ser definida como a geração e a aplicação criativas de ideias com potencial de melhoria significativa em produtos, serviços, atividades, iniciativas, estruturas, programas ou políticas (CANADA SCHOOL OF PUBLIC SERVICE, 2006). As ideias são apenas o início, constituem-se a parte mais fácil da inovação, pois o grande desafio está na sua implementação, na sua execução (GOVINDARAJAN; TRIMBLE, 2010). É comum que em organizações surjam mais ideias do que a possibilidade de desenvolvê-las efetivamente, assim, a inovação não se torna realidade. O mais importante não é a inovação propriamente dita, mas a sua capacidade de criar valor público (MOORE, 2002).

Uma definição que reconhece o contexto do setor público é atribuída por Koch e Hauknes (2005), que consideram a inovação a implementação e a execução deliberadas de um conjunto de ações pela entidade, no âmbito dos objetivos e funcionalidades de suas atividades. Esses autores acreditam que uma simplificação desse conceito é dizer que inovação é fazer algo diferente e deliberado para atingir alguns objetivos. Assim, a inovação seria um processo de mudança no repertório das ações organizacionais. Essa concepção é complementada pela percepção de que as inovações devem ser novas para a própria organização, mas não necessariamente se constituir novidade para outros atores (BLOCH, 2011). A inovação pode também ser compreendida não apenas como o desenvolvimento de novas ideias, objetos ou práticas, mas pela sua adoção por uma unidade (WALKER; DAMANPOUR; DEVECE, 2010).

A definição do que é inovação difere, também, dependendo do propósito para o qual é utilizada. Por exemplo, para programas de premiação já consolidados, como o Prêmio do Serviço Público promovido pelas Nações Unidas, pode ser mais aceitável a adoção de uma definição mais estrita a fim de selecionar inovações mais significativas. Por outro lado, se o objetivo é gerar aprendizado organizacional ou resolução de problemas em curso, é mais aceitável adotar uma definição mais ampla, que fomente a melhoria contínua por meio da inovação incremental, o que não impedirá que surjam eventualmente inovações de maior porte (PATEL, 2006).

Patel (2006) utiliza o termo inovação como sinônimo de melhorias ou de boas práticas. Ele afirma que as diferenças conceituais têm pequena importância, pois as metodologias desenvolvidas para permitir a transferência de uma grande inovação podem se aplicar igualmente a uma melhoria geral. A aprendizagem e o compartilhamento de conhecimento são centrais para a disseminação de inovações e para a criação de organizações inovadoras. Além disso, as conotações positivas do conceito de inovação podem por si só facilitar a melhoria e a mudança nas instituições. 
A questão da difusão de inovações apresenta grande diferença entre o setor público e o privado. Enquanto no setor privado a visão é a de que as inovações devem ser protegidas de cópia para aumentar os lucros temporários provenientes do monopólio, no setor público ocorre o oposto. Na administração pública a disseminação das inovações pode levar a um melhor uso dos recursos (MOORE, 2002; MULGAN; ALBURY, 2003; BLOCH; BUGGE, 2013). Existem diversos fatores que fornecem suporte à inovação no setor público. Pode-se criar um ambiente para a inovação por meio de estratégias que motivem os servidores, que moldem a cultura organizacional e que definam formas de resposta a desafios externos (PATEL, 2006; GLOR, 2001). É relevante apoiar a formação de grupos de interesses e redes que disseminem e desenvolvam o pensamento inovador na organização, assim como mecanismos institucionais que aumentem a velocidade e a frequência com que as inovações ocorrem (PATEL, 2006).

A maioria das inovações no setor público pode ser considerada incremental (MULGAN; ALBURY, 2003). Estas raramente alteram a dinâmica dentro das organizações ou a forma como elas estão estruturadas, mas são essenciais para a melhoria contínua nos serviços públicos. As inovações também podem ser radicais, quando estabelecem novas formas de gerir ou prover determinados serviços. Por último, as inovações podem ser sistêmicas ou transformacionais, geradas pelo surgimento de novas tecnologias, que transformam setores, levando à emergência de novas estruturas de trabalho e organizacionais, podendo ser fruto de mudança nas políticas ou na cultura organizacional. Há, ainda, destaque para a questão da verticalidade da inovação, ou seja, a inovação top-down, na qual as transformações são conduzidas por um sistema por meio de prescrição, regulação e suporte, e a inovação bottom-up, originada em uma organização ou rede dentro do sistema, necessitando ser difundida para outras organizações (MULGAN; ALBURY, 2003).

Dois modelos de contextos institucionais nos quais a inovação ocorre na gestão pública podem ser identificados (MOORE, 2005): um relacionado a inovações que provocam um rompimento, que geram um grande impacto, e outro com enfoque em organizações inovadoras, que possuem a abordagem de melhoria contínua. Os dois modelos tratam de duas coisas sutilmente diferentes. No primeiro o enfoque é dado no que se constitui uma inovação importante e como se pode viabilizar a sua disseminação. No segundo modelo o foco passa a ser a estrutura organizacional, a cultura e outros aspectos relativos às organizações. Ao se compreenderem os dois modelos, percebe-se que as tentativas de disseminação das inovações devem incluir estratégias que conciliem a inovação propriamente dita com questões organizacionais (MOORE, 2005; PATEL, 2006). 
Pode-se distinguir quatro diferentes tipos de inovação: de produto, de processo, organizacional e de comunicação. A inovação de produto refere-se à introdução de um novo serviço ou produto, ou à melhoria significativa de algum já existente. A de processo é a introdução de um método para a produção ou provisão de serviços que seja nova ou tenha sofrido uma melhoria em relação aos processos já existentes. A inovação organizacional é a implementação de um novo método para organizar ou gerenciar o trabalho que difere significativamente dos métodos já existentes. E, por fim, a inovação de comunicação consiste em novos métodos de promoção da organização ou seus produtos e serviços, ou novos métodos para influenciar comportamentos (BLOCH, 2011).

No Brasil, a inovação tem sido estimulada pelo Concurso Inovação na Gestão Pública Federal desde 1996. Ferrarezi e Amorim (2007, p. 33) analisaram 11 edições do concurso e verificaram que alguns princípios relativos à inovação no setor público permaneceram inalterados durante esse período: “[...] foco no cidadão, participação social, realização de parcerias, desenvolvimento de pessoas, planejamento e gestão estratégica, melhoria de processos de trabalho, preocupação com os resultados, os custos e a gestão de informações.”

\subsection{PROGRAMA NETUNO}

A Marinha, ao longo dos anos, acompanhou o desenvolvimento de novas ferramentas na administração pública, implementando programas adaptados às suas necessidades (BRASIL, 2011). As mudanças de políticas e programas norteadores da gestão visaram à constante melhoria de resultados e à inovação em processos de gestão. Dessa maneira, as dinâmicas de gestão foram gradativamente alteradas, mas sempre acompanhando as diretrizes da gestão pública federal - conforme demonstrado na Figura 2. 
Figura 2 - Programas da Marinha do Brasil e do Governo Federal

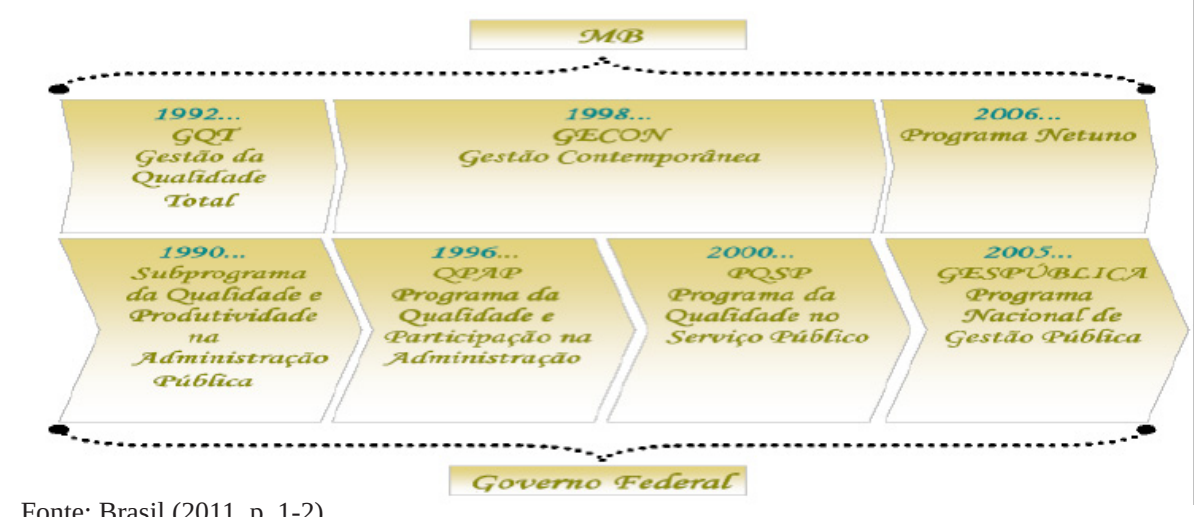

Fonte: Brasil (2011, p. 1-2).

Em 2005, o Governo Federal estabeleceu, por meio do Decreto n. 5.378, o Gespública, com a finalidade de contribuir para a melhoria dos serviços prestados aos cidadãos e para o aumento da competitividade do País.

O Programa Netuno foi elaborado com base no Gespública e consiste em um processo administrativo destinado a aprimorar a gestão das organizações militares da MB. O Programa tem como diretrizes básicas: a capacitação profissional, o aperfeiçoamento da estrutura administrativa, a valorização do elemento humano, assim como a racionalização de custos e o combate ao desperdício, na busca pela austeridade financeira (BRASIL, 2013). Atualmente, o Programa Netuno utiliza diversas ferramentas de gestão, que vêm se disseminando para um número cada vez maior de organizações militares, como: o Planejamento Estratégico Organizacional, a Análise e Melhoria de Processos, a Carta de Serviços, o Conselho de Gestão, a Pesquisa de Clima Organizacional e o Ciclo de Avaliação e Melhoria. Para seu fortalecimento e constante aperfeiçoamento, as seguintes ações são realizadas (BRASIL, 2011):

a) capacitação: tem a finalidade de tornar os colaboradores aptos a aplicarem as ferramentas disponibilizadas pelo Programa nas OMs e a multiplicarem o conhecimento por meio de treinamentos internos;

b) institucionalização: busca sedimentar a cultura de excelência em gestão e a utilização das ferramentas, de maneira que não ocorram retrocessos na implementação do Programa quando da mudança de gestores;

c) validação e premiação: visa confirmar as boas práticas e motivar a sua concepção e implementação; 
d) publicidade dos resultados: permite que o sucesso auferido por algumas organizações seja disseminado, servindo como referência e funcionando como motivador, ao promover o reconhecimento das iniciativas, assim amplificando o uso das práticas para outras OM.

Em alinhamento com essas ações está a criação de um banco de iniciativas inovadoras no sítio do Programa Netuno. Esse banco fomenta o uso do Programa, permitindo a realização de benchmarking entre as organizações, o que potencializa o aprendizado organizacional e incentiva a cultura de inovação. As iniciativas são categorizadas pelos critérios de excelência estabelecidos. Os critérios e orientações do Programa Netuno são estruturados tendo como base o IAGP, havendo uma customização para a Marinha do Brasil. A dinâmica de autoavaliação utiliza a lista de verificação contida na sistemática de Inspeções Administrativo-Militares (IAM), ${ }^{2}$ que se trata de ferramenta gerencial já bastante testada, sedimentada e aprovada no âmbito da Força (BRASIL, 2011). O modelo de excelência adotado pelo Programa Netuno e seus respectivos critérios estão representados na Figura 3.

Figura 3 - Modelo de excelência em gestão do Programa Netuno

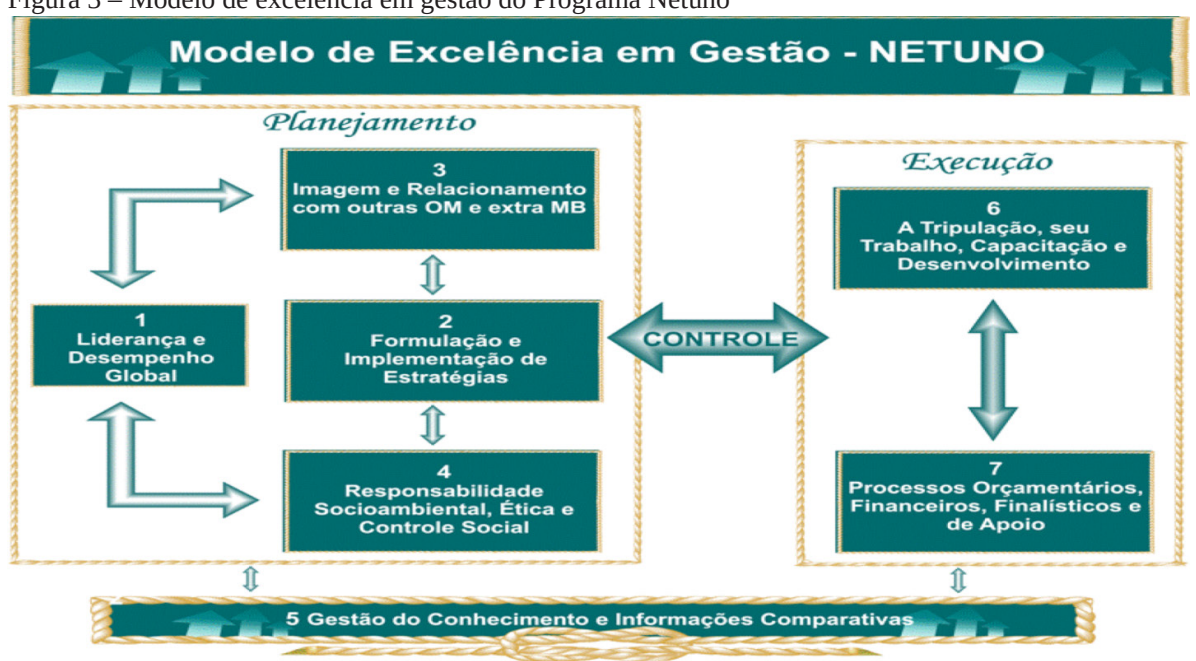

Fonte: Brasil (2014a).

\section{METODOLOGIA}

A pesquisa foi realizada por meio de estudo de caso, de caráter descritivo, considerando que se buscou demonstrar como o Programa Netuno tem incentivado a 
implementação de iniciativas inovadoras nas organizações da Marinha (YIN, 1993, 2005). A unidade de análise utilizada é o próprio Programa Netuno. Apesar de ser um caso único, o Programa abrange 366 Organizações Militares (OMs). Para considerar o que são iniciativas inovadoras, neste estudo utilizou-se a definição adotada por Patel (2006), que abrange as melhorias e as boas práticas.

Para a coleta dos dados, foi utilizada a netnografia, ${ }^{3}$ levantando-se as iniciativas inovadoras no sítio do Programa Netuno. Essas iniciativas são publicadas no sítio após análise, pelos assessores do Programa, das listas de verificação preenchidas por ocasião das avaliações das OMs. Em alguns casos, as próprias organizações encaminharam as suas iniciativas pelo canal de relacionamento do Programa Netuno. Os condutores do Programa classificaram essas iniciativas de acordo com os critérios adotados pelo instrumento de avaliação de seu modelo de excelência. Foram analisadas um total de 145 iniciativas, implementadas e divulgadas de novembro de 2010 a junho de 2014.

O tratamento de dados foi realizado por meio de análise de conteúdo (BARDIN, 2010). Nesta utilizou-se grade fechada, e a interpretação dos resultados foi realizada por emparelhamento (pattern-matching). Para a avaliação das iniciativas, foram estabelecidos como categorias de análise os tipos de inovação apresentados por Bloch (2011) e os princípios identificados por Ferrarezi e Amorim (2007), que permaneceram inalterados nos Concursos Inovação na Gestão Pública Federal, promovidos pela ENAP. Para apoio à analise, foi utilizado o software atlas.ti.

\section{ANÁLISE DOS RESULTADOS}

A elevada frequência de geração de inovações na Marinha do Brasil é característica de algumas décadas, entre as quais estão as inovações tecnológicas e de gestão. No âmbito da tecnologia, destaca-se o Programa Nuclear da Marinha, que desenvolveu as tecnologias relativas aos sistemas de propulsão dos futuros submarinos nucleares brasileiros (PESCE, 2013). No âmbito da gestão, pode ser citado o Sistema do Plano Diretor (SPD), criado há mais de 50 anos, que buscava integrar objetivos, ações necessárias para a sua realização, custos e recursos orçamentários, marcando a introdução do planejamento na gestão orçamentária (OLIVEIRA, 2000). Segundo Oliveira (2000, p. 172) “[...] o Plano Diretor foi a primeira iniciativa do gênero aplicada em nível ministerial no país.” Outra inovação de grande vulto foi o Sistema $\mathrm{OMPS}^{4}$, que permitiu a conquista pela Marinha, em 1999, do prêmio Hélio Beltrão - hoje denominado Concurso Inovação na Gestão Pública Federal (FERRAREZI; 
AMORIM, 2007; SILVA; LEAL; FERREIRA, 2011). Naquela época, a MB já estava preocupada com os custos de seus processos e de suas unidades. De forma geral, na administração pública, a implementação de sistemas de custos se tornou mais presente apenas a partir da publicação das Normas Brasileiras de Contabilidade Aplicadas ao Setor Público (NBCASP) em 2008 (DARÓS; PEREIRA, 2011).

Em 2006, a Marinha do Brasil criou o Programa Netuno, que estimula uma série de inovações. Algumas inovações levam a um rompimento, conforme um dos modelos abordados por Moore (2005). Estas são representadas pelos próprios instrumentos do Programa Netuno, que foram sendo adotados ao longo dos anos de funcionamento do Programa e trazem novas concepções à gestão das organizações militares.

O Conselho de Gestão - anteriormente denominado Conselho Econômico - permitiu uma ruptura com as formas tradicionais de prestação de contas, que anteriormente priorizava a verificação de documentos e saldos. No primeiro momento, o enfoque visava apenas à conformidade - por exemplo, se os cálculos estavam corretos e a documentação, de acordo com as normas. No segundo momento o foco foi ampliado, passaram a ser tratados assuntos de nível macro dentro da organização, discutindo-se a gestão estratégica, suas metas e indicadores. Dessa forma, a tomada de decisão passou a ser realizada com maior embasamento e agilidade, amparada em informações concretas e com os responsáveis presentes por cada setor.

O Planejamento Estratégico Organizacional (PEO) permite que a organização passe a seguir uma direção única, comunicada para os demais níveis hierárquicos. As próprias técnicas de gestão estratégica vêm sofrendo evoluções na Marinha. Um exemplo disso é uma inovação estabelecida em 2013, o Plano de Acompanhamento de Gestão (PAG), que descreve “[...] como pôr em prática o planejamento estratégico organizacional, devendo conter atividades, procedimentos, prazos, responsáveis e recursos necessários para o seu cumprimento, orientando ações em um horizonte de curto prazo (um exercício).” (BRASIL, 2013, p. 6-20). O uso efetivo desse instrumento pode servir como elo entre o PEO e os sistemas gerenciais da organização, tornando a estratégia mais presente no cotidiano das OMs (SOUZA, 2013).

A Análise e Melhoria de Processos permite compreender como funcionam os processos e como podem ser gerenciados e aprimorados, buscando-se obter melhores resultados. A visão do processo é uma maneira de identificar e aperfeiçoar as interfaces funcionais, que são os pontos nos quais o trabalho que está sendo realizado é transferido de um setor para o seguinte. Tal método também se constitui uma ferramenta importante para identificar as competências necessárias para cada função. 
A Pesquisa de Clima Organizacional potencializou o senso de valorização dos servidores, conforme as próprias diretrizes do Programa Netuno. Esse instrumento permitiu um maior conhecimento dos anseios dos colaboradores e, consequentemente, a identificação por parte da administração das ações necessárias para o aumento de sua satisfação.

A Carta de Serviços tem o objetivo de informar ao cidadão os serviços prestados pela organização, as formas de acesso e os respectivos compromissos e padrões de qualidade de atendimento ao público (BRASIL, 2009a). Esta se alinha à gestão para resultados mediante o estabelecimento de padrões de qualidade, estimulando o acesso aos serviços e possibilitando o atendimento de maior parcela da população. Além disso, ao fornecer informações claras e precisas sobre os serviços prestados, permite a comparabilidade, criando-se condições para a realização do benchmarking ${ }^{5}$ com organizações que prestam o mesmo tipo de serviço e que sejam reconhecidas pela elevada qualidade em suas respectivas áreas (SOUZA; PARREIRA, 2014). Atualmente, o sítio do Programa Netuno na intranet possui Cartas de Serviços de mais de 50 OMs, o que evidencia a ampla disseminação desse instrumento.

O Ciclo de Avaliação e Melhoria da Gestão - ferramenta amplamente utilizada em outros programas de qualidade, públicos e privados - permite um diagnóstico sobre o estado atual das práticas de gestão da organização, levando à reflexão sobre possíveis oportunidades de melhoria. Esse estado de constante avaliação-reflexão permite potencializar a cultura da inovação nas organizações, ao estimular o surgimento de novas ideias e a sistematização da sua implementação.

Assim, as inovações incrementais, conforme o segundo modelo abordado por Moore (2005), são fomentadas de maneira generalizada e constante, sendo difundidas entre as organizações da Marinha do Brasil.

A pesquisa netnográfica revela algumas iniciativas inovadoras implementadas e difundidas por diversas organizações no sítio do Programa Netuno. Verifica-se que as iniciativas são concentradas em 55 organizações da MB, sendo distribuídas de acordo com os critérios adotados pelo Programa - conforme demonstrado no Gráfico 1. A temática de maior destaque é aquela que reflete o foco no desenvolvimento da força de trabalho, fato que corrobora as diretrizes do Programa Netuno - relacionadas à capacitação profissional e à valorização do elemento humano. 
Gráfico 1 - Iniciativas inovadoras por critério do Programa Netuno

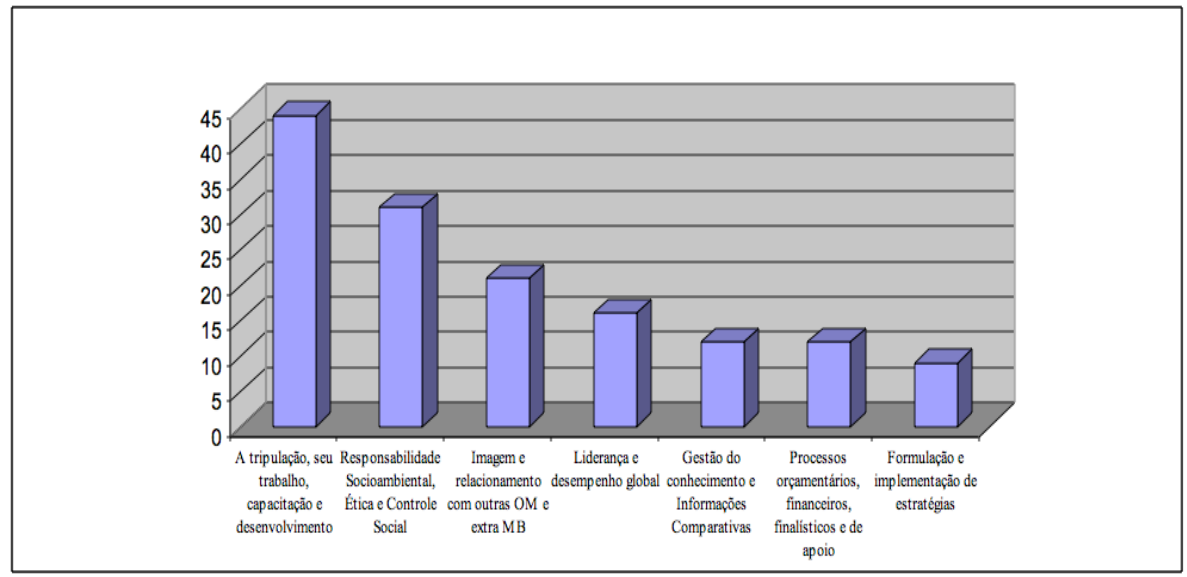

Fonte: os autores.

Em relação à tipologia empregada por Bloch (2011), a Tabela 1 ilustra a distribuição encontrada na pesquisa. Os resultados demonstram uma predominância da inovação organizacional, que está relacionada à implementação de novos métodos para organizar ou gerenciar o trabalho, mediante melhorias nos sistemas ou nas estruturas organizacionais (BLOCH, 2011; BLOCH; BUGGE, 2013). Tal resultado corrobora aquele encontrado por Sousa et al. (2013) ao analisar iniciativas do Concurso de Inovação na Administração Pública Federal.

Tabela 1 - Tipos de inovação

\begin{tabular}{lll}
\hline \multicolumn{1}{c}{ Tipo de Inovação } & \multicolumn{1}{c}{ Quantidade } & Percentual \\
\hline Organizacional & 68 & 47 \\
Processo & 45 & 31 \\
Produto & 20 & 14 \\
Comunicação & 12 & 8 \\
Total & 145 & 100 \\
\hline Fonte: os autores.
\end{tabular}

Fonte: os autores.

O Quadro 1 apresenta resumidamente, como exemplo, algumas inovações do tipo organizacional encontradas. 
Flávio Sergio Rezende Nunes de Souza et al.

Quadro 1 - Exemplos de inovações organizacionais

\begin{tabular}{|c|c|c|}
\hline Iniciativa & Organização Militar & Descrição da iniciativa \\
\hline $\begin{array}{l}\text { Divulgação } \\
\text { por meio de } \\
\text { pop-up de } \\
\text { conteúdo de } \\
\text { liderança }\end{array}$ & $\begin{array}{l}\text { Comando da Força } \\
\text { de Fuzileiros da } \\
\text { Esquadra }\end{array}$ & $\begin{array}{l}\text { Disponibilizado conteúdo nas estações de trabalho com o obje- } \\
\text { tivo de consolidar os valores e princípios doutrinários no âmbito } \\
\text { da OM, de modo a contribuir para que o pessoal trabalhe de } \\
\text { forma harmônica, atendendo aos valores organizacionais consi- } \\
\text { derados importantes. }\end{array}$ \\
\hline $\begin{array}{l}\text { Workshop } \\
\text { de liderança }\end{array}$ & $\begin{array}{l}\text { Navio Aeródromo } \\
\text { São Paulo }\end{array}$ & $\begin{array}{l}\text { Realizados debates sobre vários temas relacionados à liderança, } \\
\text { assim, criando um fórum de discussão sobre as práticas e ensina- } \\
\text { mentos relacionados ao tema. }\end{array}$ \\
\hline $\begin{array}{l}\text { Pista de } \\
\text { liderança }\end{array}$ & $\begin{array}{l}\text { Centro de Instrução } \\
\text { Almirante Sylvio de } \\
\text { Camargo }\end{array}$ & $\begin{array}{l}\text { A pista de liderança é dividida em } 10 \text { estações, nas quais cada } \\
\text { grupo é colocado face a situações específicas a serem resolvidas. } \\
\text { Todos os eventos são observados por controladores a partir de } \\
\text { uma passarela elevada que possibilita a avaliação das atividades. } \\
\text { Ao final, em uma reunião de crítica, são comentados os aspec- } \\
\text { tos relevantes de cada estação, bem como do exercício em sua } \\
\text { totalidade, sendo dispensada especial atenção à orientação dos } \\
\text { militares que mostraram necessitar desenvolver a liderança ou } \\
\text { têm alguma dificuldade de trabalhar em equipe. }\end{array}$ \\
\hline $\begin{array}{l}\text { Premiação } \\
\text { sobre o } \\
\text { pensamento } \\
\text { criativo e a } \\
\text { inovação }\end{array}$ & $\begin{array}{l}\text { Centro de Intendên- } \\
\text { cia da Marinha em } \\
\text { Rio Grande }\end{array}$ & $\begin{array}{l}\text { Estabelecimento de normatização interna com o objetivo de } \\
\text { fomentar e premiar o pensamento criativo e a inovação nas } \\
\text { atividades da OM. }\end{array}$ \\
\hline $\begin{array}{l}\text { Novo sis- } \\
\text { tema de } \\
\text { captação } \\
\text { de água da } \\
\text { chuva }\end{array}$ & $\begin{array}{l}\text { Delegacia da Capi- } \\
\text { tania dos Portos de } \\
\text { Laguna }\end{array}$ & $\begin{array}{l}\text { Incrementou seu sistema de captação de água da chuva, com a } \\
\text { finalidade de reduzir o consumo de água potável e, consequente- } \\
\text { mente, os gastos e, ainda, preservar o meio ambiente, reduzindo } \\
\text { a escassez dos recursos hídricos. }\end{array}$ \\
\hline $\begin{array}{l}\text { Banco de } \\
\text { talentos }\end{array}$ & $\begin{array}{l}\text { Hospital Naval de } \\
\text { Salvador }\end{array}$ & $\begin{array}{l}\text { Prática que proporciona a descoberta do perfil profissional de } \\
\text { cada servidor da OM. }\end{array}$ \\
\hline $\begin{array}{l}\text { Projeto } \\
\text { Cidade } \\
\text { Limpa }\end{array}$ & $\begin{array}{l}\text { Base Aérea Naval de } \\
\text { São Pedro da Aldeia }\end{array}$ & $\begin{array}{l}\text { Tem como objetivo a mitigação de risco aviário em sua Área de } \\
\text { Segurança Aeroportuária. O projeto vem apresentando ótimos } \\
\text { resultados, reduzindo drasticamente o quadro de colisões e quase } \\
\text { colisões de Aeronaves com pássaros. A principal vertente do pro- } \\
\text { jeto é a Educação Ambiental, com a finalidade de conscientizar } \\
\text { sobre os impactos que o descarte inadequado de lixo e a falta de } \\
\text { responsabilidade com o ambiente podem causar. }\end{array}$ \\
\hline
\end{tabular}

Fonte: os autores.

As inovações de processo também tiveram representatividade. Alguns exemplos desse tipo de inovação encontrados na pesquisa são ilustrados no Quadro 2. 
Quadro 2 - Exemplos de inovações de processo

\begin{tabular}{|c|c|c|}
\hline Iniciativa & Organização Militar & Descrição da iniciativa \\
\hline $\begin{array}{l}\text { Balanced Sco- } \\
\text { recard }\end{array}$ & $\begin{array}{l}\text { Centro de Intendência } \\
\text { da Marinha em São } \\
\text { Pedro da Aldeia }\end{array}$ & $\begin{array}{l}\text { Implantação do Balanced Scorecard (BSC) como ferra- } \\
\text { menta para o processo de gestão da estratégia e de medição } \\
\text { do desempenho organizacional. }\end{array}$ \\
\hline $\begin{array}{l}\text { Sistema de men- } \\
\text { toring na elabo- } \\
\text { ração do Plano } \\
\text { de Melhoria de } \\
\text { Gestão }\end{array}$ & $\begin{array}{l}\text { Hospital Naval de } \\
\text { Salvador }\end{array}$ & $\begin{array}{l}\text { A utilização de mentoring na elaboração do Plano de Me- } \\
\text { lhoria da Gestão propicia a gestão do conhecimento na } \\
\text { OM, permitindo continuidade à implementação das práticas } \\
\text { e maior comprometimento dos agentes. }\end{array}$ \\
\hline $\begin{array}{l}\text { Normatização } \\
\text { do processo } \\
\text { de tomada de } \\
\text { decisão }\end{array}$ & $\begin{array}{l}\text { Policlínica Naval de } \\
\text { Campo Grande }\end{array}$ & $\begin{array}{l}\text { Norma em que estão detalhadas todas as etapas do pro- } \\
\text { cesso de decisão, desde a apresentação da proposta, pelo } \\
\text { setor responsável, até a sua divulgação aos interessados por } \\
\text { diversos meios de comunicação. }\end{array}$ \\
\hline $\begin{array}{l}\text { Prêmio Controle } \\
\text { Naval do Tráfe- } \\
\text { go Marítimo }\end{array}$ & $\begin{array}{l}\text { Comando do Controle } \\
\text { Naval do Tráfego } \\
\text { Marítimo }\end{array}$ & $\begin{array}{l}\text { Esse prêmio estimula a obtenção de melhores resultados } \\
\text { pelas unidades no processo de apoio ao Sistema de Infor- } \\
\text { mações sobre o Tráfego Marítimo (Sistram), contribuindo } \\
\text { para a segurança da navegação e para a salvaguarda da vida } \\
\text { humana no mar. }\end{array}$ \\
\hline $\begin{array}{l}\text { Avaliação de } \\
\text { desempenho } \\
360^{\circ}\end{array}$ & $\begin{array}{l}\text { Diretoria de Pessoal } \\
\text { Civil da Marinha }\end{array}$ & $\begin{array}{l}\text { Implementação da Avaliação de Desempenho } 360^{\circ} \text { para os } \\
\text { que trabalham com o gerenciamento de Pessoal Civil nas } \\
\text { OMs da MB. }\end{array}$ \\
\hline $\begin{array}{l}\text { Instrução para } \\
\text { o atendimento } \\
\text { ao público por } \\
\text { vídeo }\end{array}$ & $\begin{array}{l}\text { Diretoria de Portos e } \\
\text { Costas }\end{array}$ & $\begin{array}{l}\text { A instrução realizada por vídeo permite o aprimoramento } \\
\text { da qualidade dos serviços prestados pelas Capitanias dos } \\
\text { Portos, suas Delegacias e Agências. As aulas demonstram } \\
\text { situações similares às cotidianas, procurando enfatizar } \\
\text { atitudes corretas que contribuam para promover um bom } \\
\text { atendimento aos usuários dos serviços. }\end{array}$ \\
\hline $\begin{array}{l}\text { Pesquisas de } \\
\text { satisfação }\end{array}$ & $\begin{array}{l}\text { Diretoria de Assistên- } \\
\text { cia Social da Marinha }\end{array}$ & $\begin{array}{l}\text { Aferir o grau de satisfação em relação ao assessoramento } \\
\text { e a orientações técnicas oferecidos por essa diretoria espe- } \\
\text { cializada. }\end{array}$ \\
\hline
\end{tabular}

Fonte: os autores.

A inovação em produto e de comunicação foram os tipos menos frequentes no estudo, fato que pode ser justificado em razão de a Marinha, de maneira geral, prestar um serviço predominantemente intangível, relacionado à segurança e à defesa nacional, que pode ser classificado como um resultado social, um dos tipos de criação de valor público (KELLY; MULGAN; MUERS, 2002). Tal fato dificulta a visualização de serviços tangíveis, que possam ser classificados como produtos, assim como formas de comunicar sobre estes aos usuários. O mesmo ocorre em alguns casos mais 
específicos, principalmente, em relação àqueles que atendem diretamente aos usuários, como unidades de ensino, saúde e centros culturais.

Em relação à comunicação, metade das iniciativas estavam associadas ao critério “Responsabilidade Socioambiental, Ética e Controle Social”, o que demonstra a preocupação em se manter alto grau de legitimidade das OMs com a sociedade, o que também se constitui uma das formas de criação de valor público (KELLY; MULGAN; MUERS, 2002). Exemplos de iniciativas classificadas como produto são novos cursos disponibilizados, o Legismar ${ }^{6}$; e o Flash doutrinário do Corpo de Fuzileiros Navais (CFN). ${ }^{7}$ No caso das classificadas como comunicação, pode-se citar o guia de marcação de consultas do Centro Médico Assistencial da Marinha, que orienta sobre o acesso ao atendimento e fornece a relação de policlínicas e serviços, as cartas web da Comissão de Promoção de Oficiais, que disponibilizam por processo informatizado resultados de avaliações dos oficiais, e a revista $O$ Briefing do Navio Aeródromo São Paulo, que contém matérias sobre a segurança da aviação e as atividades realizadas pelo navio.

Ao analisar os princípios identificados por Ferrarezi e Amorim (2007), foi verificado que algumas inovações se relacionam a mais de um princípio. Todos os princípios foram contemplados nos resultados, e não houve nenhuma iniciativa que não apresentasse nenhum dos princípios. A Tabela 2 ilustra os resultados encontrados.

Tabela 2 - Princípios observados

\begin{tabular}{lcr}
\hline Princípios & Frequência & \multicolumn{2}{c}{ Percentual } \\
\hline Desenvolvimento de pessoas & 72 & $21 \%$ \\
Melhoria de processos de trabalho & 68 & $20 \%$ \\
Preocupação com resultados & 52 & $15 \%$ \\
Gestão das informações & 46 & $13 \%$ \\
Foco no cidadão & 36 & $11 \%$ \\
Participação Social & 26 & $8 \%$ \\
Realização de parcerias & 24 & $7 \%$ \\
Planejamento e gestao estrategica & 9 & $3 \%$ \\
Preocupação com custos & 8 & $2 \%$ \\
Total & 341 & $100 \%$ \\
\hline
\end{tabular}

Fonte: os autores.

O princípio mais presente, permeando 50\% das iniciativas, foi o desenvolvimento de pessoas, o que reforça novamente a relação encontrada com diretrizes do Programa Netuno sobre a valorização da força de trabalho. Em seguida, percebe-se uma grande frequência da melhoria dos processos de trabalho, encontrada em 47\% das iniciativas. Tal princípio está relacionado ao ciclo de avaliação e melhoria promovido pelo Programa, que ocorre a cada dois anos, por ocasião das Inspeções Adminis- 
trativas, quando os processos organizacionais são avaliados buscando-se oportunidades de melhoria.

\section{CONSIDERAÇÕES FINAIS}

A quantidade de iniciativas apresentadas por uma grande variedade de organizações evidencia que o Programa Netuno tem criado mecanismos institucionais que permitem o surgimento de um ambiente de inovação. Exemplos de mecanismos são o banco de iniciativas no site do Programa e as demais disseminações realizadas nas palestras, cursos e outros meios de divulgação institucionais da Marinha, que têm fomentado a difusão das inovações entre as organizações dessa Força. Dessa forma, as unidades que efetivamente participam do Programa são incentivadas ao desenvolvimento do aprendizado organizacional, facilitando o surgimento da cultura de inovação. O Diagrama 2 ilustra a relação entre as ferramentas do Programa Netuno e o surgimento de iniciativas inovadoras nas organizações.

Diagrama 2 - Influência do Programa Netuno na inovação das organizações da Marinha

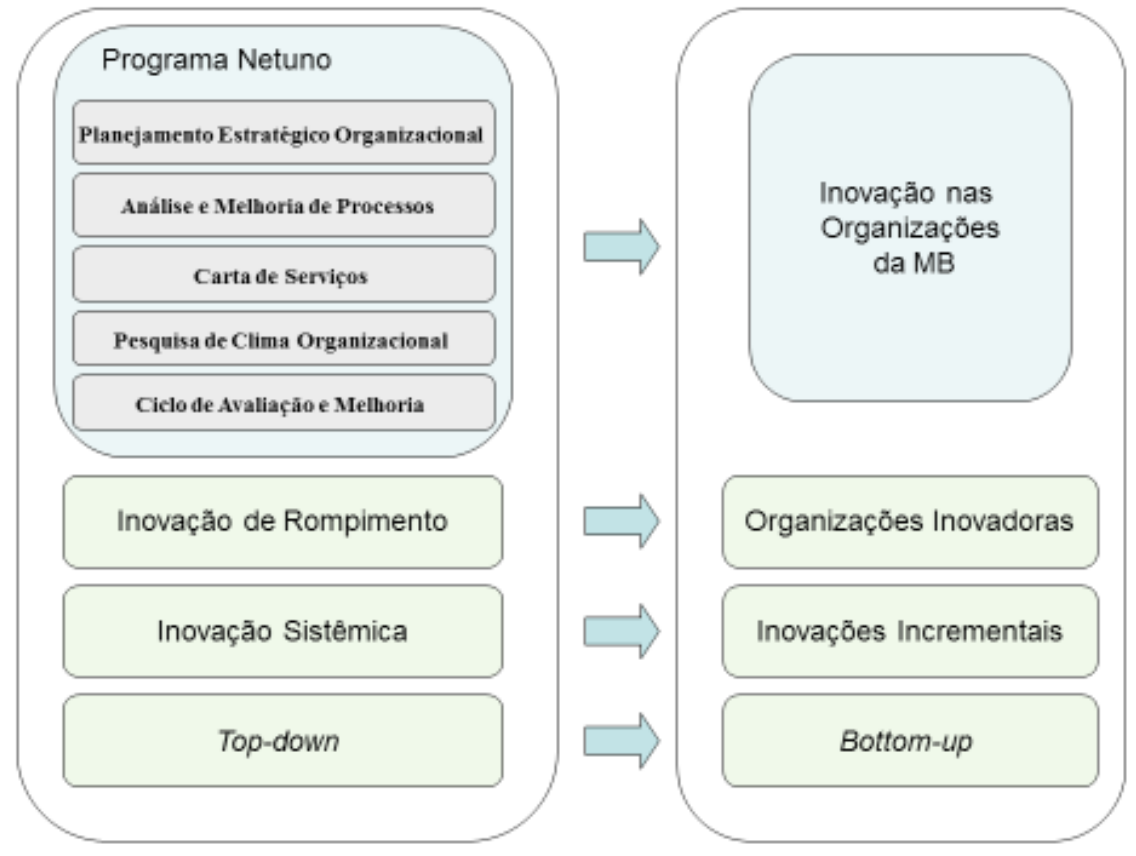

Fonte: adaptado de Moore (2005) e Mulgan e Albury (2003). 
O Programa Netuno é oriundo da existência de uma nova regulamentação, aliado à intenção estratégica de transformação organizacional na Instituição. Dessa forma, consistiu em mudanças nas diretrizes gerenciais com a finalidade de impactar a cultura organizacional da Força. A gestão deixa de ter foco nas rotinas, visando à gestão estratégica. Assim, o foco passa a estar no alcance de objetivos macro, alinhados à sua missão. A abordagem de prestação de contas passa a ser ampliada, por meio de uma efetiva gestão para resultados. O diagnóstico organizacional é direcionado para a identificação de oportunidades de melhoria, e a implementação de ações decorrentes torna-se um processo rotineiro, que leva à melhoria, contínua. Os compromissos assumidos com os cidadãos e organizações clientes passam a estar presentes no dia a dia das organizações. Em razão dessas características, pode-se considerar o Programa uma inovação sistêmica.

Como inovação sistêmica, o Programa Netuno influencia as demais organizações da Marinha na implementação de inovações incrementais (MULGAN; ALBURY, 2003). Da mesma forma, ele constitui-se uma inovação de rompimento, que facilita o surgimento de organizações inovadoras (MOORE, 2005). Além disso, verifica-se que o Programa estabelece uma sistemática que prescreve, regula e suporta as mudanças, constituindo-se uma inovação top-down, enquanto algumas inovações são originadas nas organizações que utilizam a sistemática, consistindo em inovações bottom-up (MULGAN; ALBURY, 2003).

Diversos autores afirmam que mais importante do que a novidade e o vulto das inovações, é que sejam efetivamente implementadas e disseminadas, para que possam ser utilizadas por outras organizações no setor público (PATEL, 2006; BLOCH; BUGGE, 2013). O Programa Netuno tem facilitado a implementação e a divulgação dessas práticas ao realizar suas ações de capacitação e divulgação, incentivando e mantendo uma estrutura capaz de apoiar as organizações da Marinha do Brasil nessa empreitada. O Programa disponibiliza as ferramentas e a capacitação adequadas para a sua utilização. No entanto, cabe às lideranças das organizações utilizá-las. Desse modo, faz-se relevante a inserção da percepção de sua importância na cultura organizacional, de forma que o Programa não seja abandonado quando da mudança das lideranças.

Por fim, vale destacar que as observações apresentadas no presente estudo se concentraram em 55 organizações da Marinha. Assim, sugere-se que o Programa intensifique suas ações, buscando atingir um maior número de organizações, e que aquelas que já implementaram os instrumentos divulguem seus resultados, servindo como exemplo para as demais. As iniciativas, sistematizadas e trabalhadas sob o modelo do Programa, podem proporcionar cada vez mais resultados concretos como a 
modernização gerencial e o aumento da prontidão operativa e da capacidade de combate da Força, a elevação da qualidade de vida do pessoal e o cumprimento das atribuições constitucionais em atendimento aos anseios da sociedade brasileira. Para pesquisas futuras, sugere-se explorar os fatores que facilitam a implementação de inovações nas organizações, assim como dificuldades que estas possam ter na sua adoção.

\section{Notas explicativas:}

${ }^{1}$ Acrônimo de Plan, Do, Check, Act, ou seja, planejar, fazer, checar e agir.

${ }^{2}$ Inspeção realizada pelo Comando Imediatamente Superior, ou por quem este determinar, periodicamente, nas organizações subordinadas, com os propósitos de: avaliar a eficiência, a eficácia e a efetividade das ações organizacionais; verificar, in loco, os problemas mais significativos enfrentados e orientar as suas soluções; e, verificar aspectos gerais do pessoal e do material (BRASIL, 2009b).

${ }^{3}$ O neologismo "netnografia” (nethnography = net + ethnography) foi originalmente cunhado por um grupo de pesquisadores norte-americanos em 1995, buscando preservar os detalhes ricos da observação em campo etnográfico usando o meio eletrônico (BRAGA, 2007). Essa metodologia tem a intenção de abordar as mesmas características do método etnográfico (ou seja, estudos de práticas sociais, de artefatos que instituem cultura), voltando a atenção para o ambiente no qual a comunicação é mediada pela internet (AMARAL; NATAL; VIANA, 2009). ${ }^{4}$ Organização Militar Prestadora de Serviço (OMPS) é a organização militar que presta serviços a outras organizações militares e, eventualmente, a organizações não vinculadas à Marinha, efetuando a cobrança pelos serviços prestados. Pode atuar nas áreas industrial, de pesquisa e desenvolvimento de ciência e tecnologia, hospitalar, de abastecimento ou de serviços especiais (BRASIL, 2008).

${ }^{5}$ Benchmarking pode ser definido como a procura contínua de melhores métodos e práticas que produzem um maior desempenho quando adaptados na própria organização (BRASIL, 2013, p. 1-28).

${ }^{6}$ O Legismar é um sistema voltado para a gestão do conhecimento, direcionado a todos os integrantes da Marinha e desenvolvido, dentro das condicionantes de utilização de software livre e de gestão integrada da informação. Tem como objetivos: proporcionar a consulta às legislações e aos documentos administrativos de interesse institucional; permitir a manutenção descentralizada desses documentos pelas próprias OMs que os elaboraram; e, manter um histórico das legislações e documentos administrativos de interesse da Marinha.

${ }^{7}$ É um consagrado periódico publicado pelo Comando do Desenvolvimento Doutrinário do CFN que tem a finalidade de promover a atualização do conhecimento profissional no âmbito dos oficiais do CFN, particularmente em relação aos aspectos doutrinários, referentes aos Grupamentos Operativos de Fuzileiros Navais. 


\section{REFERÊNCIAS}

AMARAL, A.; NATAL, G.; VIANA, L. Netnografia como aporte metodológico da pesquisa em comunicação digital. Comunicação, v. 6, n. 1, 2009.

BARDIN, L. Análise de conteúdo. Lisboa: Edições 70, 2010.

BRAGA, A. Usos e consumo de meios digitais entre participantes de weblogs: uma proposta metodológica. In: ENCONTRO DA COMPÓS, 16., 2007, Curitiba. Anais... Curitiba: Compós, 2007. Disponível em: <http://www.compos.org.br/data/ biblioteca_162.pdf>. Acesso em: 20 jun. 2014.

BRANDÃO, S.; BRUNO-FARIA, M. Inovação no setor público: análise da produção científica em peridiócos nacionais e internacionais da área de administração. Revista de Administração Pública, v. 47, n. 1, p. 227-248, 2013.

BRASIL. Decreto n. 6.932, de 11 de agosto de 2009. Dispõe sobre a simplificação do atendimento público prestado ao cidadão, ratifica a dispensa do reconhecimento de firma em documentos produzidos no Brasil, institui a "Carta de Serviços ao Cidadão” e dá outras providências. Diário Oficial da União, Brasília, DF, 12 ago. 2009a. Disponível em: <http://www.planalto.gov.br/ccivil_03/_ato2007-2010/2009/ decreto/d6932.htm>. Acesso em: 11 jun. 2014.

BRASIL. Marinha do Brasil. Estado-Maior da Armada. Manual de gestão administrativa da Marinha (EMA - 134). Brasília, DF, 2011.

BRASIL. Marinha do Brasil. Estado-Maior da Armada. Manual de visitas, inspeções e reuniões funcionais da Marinha (EMA -130). Brasília, DF, 2009b.

BRASIL. Marinha do Brasil. Modelo de Gestão do Programa Netuno. Rio de Janeiro, 2014a. Disponível em: < http://www.programanetuno.mar.mil. br/?q=node/49\#overlay-context=node\%3Fq\%3Dnode >. Acesso em: 09 jun. 2014.

BRASIL. Marinha do Brasil. Secretaria-Geral da Marinha. Normas Gerais de Administração (SGM-107). Brasília, DF, 2013.

BRASIL. Marinha do Brasil. Secretaria-Geral da Marinha. Normas sobre contabilidade das organizações militares prestadoras de serviço (OMPS) (SGM-304). Brasília, DF, 2008. 
BRASIL. Ministério do Planejamento, Orçamento e Gestão. Instruções para Avaliação da Gestão Pública - 2010. Brasília, DF, 2009c.

BRASIL. Ministério do Planejamento, Orçamento e Gestão. Instrumento para Avaliação da Gestão Pública. Versão 1/2014. Brasília, DF, 2014b. Disponível em: <https://conteudo.gespublica.gov.br/pagina.2014-06-06.9098653097>. Acesso em: 03 jul. 2014.

BRASIL. Ministério do Planejamento, Orçamento e Gestão. Modelo de Excelência em Gestão Pública. Versão 1/2014. Brasília, DF, 2014c. Disponível em: <https://conteudo.gespublica.gov.br/pagina.2014-06-06.9098653097>. Acesso em: 03 jul. 2014.

BLOCH, C.; BUGGE, M. M. Public sector innovation - From theory to measurement. Structural Change and Economic Dynamics, v. 27, p. 133-145, 2013.

BLOCH, C. Measuring Public Innovation in the Nordic Countries: Copenhagen Manual. Copenhagen, Nordic Innovation Centre (NICe), Final Report, 2011.

CANADA SCHOOL OF PUBLIC SERVICE. Uma exploração inicial da literatura sobre a inovação. Cadernos ENAP, n. 30, p. 5-16, 2006.

DARÓS, L. L.; PEREIRA, A. D. S. Análise das Normas Brasileiras de Contabilidade Aplicadas ao Setor Público - NBCASP: mudanças e desafios para a contabilidade pública. In: CONGRESSO USP DE INICIAÇÃO CIENTÍFICA, 6., 2009, São Paulo. Anais... São Paulo: USP, 2009.

FERRAREZI, E.; AMORIM, S. N. D. Concurso inovação na gestão pública federal: análise de uma trajetória (1996-2006). Brasília, DF: ENAP, 2007.

FERREIRA, A. R. Análise comparativa do Prêmio Qualidade do Governo Federal com outros prêmios nacionais e internacionais de qualidade. 2003. 106 p. Dissertação (Mestrado em Gestão Pública)-Fundação Getúlio Vargas, Brasília, DF, 2003.

FUNDAÇÃO NACIONAL DA QUALIDADE. Modelo de Excelência da Gestão. 2014. Disponível em: <http://www.fnq.org.br/avalie-se/metodologia-meg/modelo-de-excelencia-da-gestao>. Acesso em: 06 jun. 2014.

GOVINDARAJAN, V.; TRIMBLE, C. O outro lado da inovação: a execução como fator crítico de sucesso. Rio de Janeiro: Elsevier, 2010.

KELLY, G.; MULGAN, G.; MUERS, S. Creating public value: an analytical framework for public service reform. London: Strategy Unit, Cabinet Office, 2002. 
KOCH, P.; HAUKNES, J. On innovation in the public sector - today and beyond. Oslo: [s.n.], 2005.

LIMA, D. H.; VARGAS, E. R. Estudos internacionais sobre inovação no setor público: como a teoria da inovação em serviços pode contribuir? Revista de Administração Pública, v. 46, n. 2, p. 385-401, 2012.

LUSTOSA, F. Brasil: 200 anos de Estado; 200 anos de administração pública; 200 anos de reformas. Revista de Administração Pública, v. 42, n. 5, p. 829-874, 2008.

MARSHALL JUNIOR, I. et al. Gestão da qualidade. 10. ed. Rio de Janeiro: Ed. FGV, 2010.

MATIAS-PEREIRA, J. Curso de gestão estratégica na administração pública. São Paulo: Atlas, 2012.

MOORE, M. H. Break-through innovations and continuous improvement: Two different models of innovative processes in the public sector. Public Money \& Management, v. 25, i. 1, p. 43-50, jan. 2005.

MOORE, M. H. Criando valor público: gestão estratégica no governo. Brasília, DF: ENAP, 2002.

MULGAN, G.; ALBURY, D. Innovation in the public sector. United Kingdom: Strategy Unit: Cabinet Office, 2003.

OLIVEIRA, M. I. O orçamento como instrumento de planejamento, execução e controle: estudo do caso do plano diretor da Marinha do Brasil. 2000. 237 p. Dissertação (Mestrado em Administração Pública)-Fundação Getúlio Vargas, Rio de Janeiro, 2000.

OLIVEIRA, P. T. C. Gestão da inovação no setor público: acumulação de capacidades tecnológicas e os processos subjacentes de aprendizagem: evidências da Secretaria do Tesouro Nacional do Brasil durante o período de 1986 a 2005. 2012. 172 p. Dissertação (Mestrado Executivo em Gestão Empresarial)-Fundação Getúlio Vargas, Rio de Janeiro, 2012.

PATEL, I. Best practices and innovation in government: perspectives, challenges and potential. 2006. Disponível em: <http://unpan1.un.org/intradoc/groups/public/ documents/un/unpan030503.pdf >. Acesso em: 12 jun. 2014. 
PESCE, E. I. Projetos da Marinha do Brasil no Plano de Articulação e Equipamentos de Defesa (PAED). Revista Marítima Brasileira, v. 133, p. 57-72, 2013.

SALAZAR, M.; HOLBROOK, A. A debate on innovation surveys. Science and Public Policy, v. 31, i. 4, p. 254-266, 2004.

SCHUMPETER, J. A teoria do desenvolvimento econômico. São Paulo: Abril Cultural, 1982.

SECCHI, L. Modelos organizacionais e reformas da administração pública. Revista de Administração Pública (RAP), v. 43, n. 2, p. 347-369, 2009.

SILVA, A. S.; LEAL, R. B.; FERREIRA, A. C. S. Avaliação de desempenho sob as perspectivas financeira e não-financeira: a gestão estratégica de uma organização militar prestadora de serviços da Marinha. Revista Contabilidade e Controladoria, Porto Alegre, v. 3, n. 2, p. 38-56, 2011. Disponível em: <http://ojs.c3sl.ufpr.br/ojs2/ index.php/rcc/article/view/20918>. Acesso em: 20 mar. 2015.

SOUSA, M. M. et al. Inovação no serviço público brasileiro: análise de 16 edições do concurso de Inovação na Administração Pública Federal. In: ENCONTRO DA ANPAD, 37., 2013, Rio de Janeiro. Anais... Rio de Janeiro: ANPAD, 2013.

SOUZA, F. S. R. N. A integração entre o planejamento estratégico e o processo de elaboração orçamentária no setor público: o caso das organizações da Marinha. 2013. 92 p. Dissertação (Mestrado em Administração)-Fundação Getúlio Vargas, Rio de Janeiro, 2013.

SOUZA, F. S. R. N.; PARREIRA, T. J. A carta de serviços ao cidadão como instrumento de melhoria do serviço público. In: CONGRESSO CONSAD DE GESTÃO PÚBLICA, 7., 2014, Brasília, DF. Anais... Brasília, DF: CONSAD, 2014.

UNITED NATIONS. Good practices and innovations in public governance. New York, 2009.

WALKER, R. M.; DAMANPOUR, F.; DEVECE, C. A. Management innovation and organizational performance: the mediating effect of performance management. Journal of Public Administration Research and Theory, muq043, 2010. YIN, R. K. Applications of case study research. London: Sage publications, 1993.

YIN, R. K. Estudo de caso: planejamento e métodos. 3. ed. Porto Alegre: Bookman, 2005. 
Como citar este artigo:

\section{ABNT}

SOUZA, Flávio Sergio Rezende Nunes et al. Programa netuno: inovação para a melhoria da gestão na marinha do Brasil. RACE, Revista de Administração, Contabilidade e Economia, Joaçaba: Ed. Unoesc, v. 15, n. 3, p. 843-870, set./dez. 2016. Disponível em: <http://editora.unoesc.edu.br/index.php/race>. Acesso em: dia/mês/ ano.

\section{APA}

Souza, F. S. R. N., Schmitt, V. G. H., Pinto, A. F., \& Favero, C. G. (2016). Programa netuno: inovação para a melhoria da gestão na marinha do Brasil. RACE, Revista de Administração, Contabilidade e Economia, 15(3), 843-870. Recuperado em dia/mês/ ano, de http://editora.unoesc.edu.br/index.php/race 